\title{
Stellera chamaejasme L. extract induces apoptosis of human lung cancer cells via activation of the death receptor-dependent pathway
}

\author{
XIAONI LIU ${ }^{1,2}$ and XIAOXIN ZHU ${ }^{3}$ \\ ${ }^{1}$ Beijing Institute of Liver Diseases and ${ }^{2}$ Beijing YouAn Hospital, Capital Medical University, Beijing 100069; \\ ${ }^{3}$ Institute of Chinese Materia Medica, China Academy of Chinese Medical Sciences, Beijing 100700, P.R. China
}

Received December 15, 2011; Accepted March 14, 2012

DOI: $10.3892 /$ etm.2012.643

\begin{abstract}
Stellera chamaejasme L. has been widely used in the treatment of lung, liver and esophageal cancer in Chinese traditional medicine. In our previous study, we found that the extract of Stellera chamaejasme L. (ESC) inhibited the growth and induced the apoptosis of human lung cancer NCI-H157 cells. In the present study, we investigated the cellular effects of an ESC-2 extract isolated from ESC in the NCI-H157 human lung cancer cell line. We found that ESC-2 inhibited the growth of NCI-H157 cells, demonstrating ESC-2-induced morphological changes in cells and reduced cell viability in a dose- and time-dependent manner. Furthermore, we observed that ESC-2 resulted in apoptosis, activation of caspase- 8 and caspase-3, and an increase in Fas expression, indicating that the NCI-H157 cell growth inhibitory activity of ESC-2 was due to death receptor-dependent pathway-mediated apoptosis, which may partly explain the anti-cancer activity of ESC-2.
\end{abstract}

\section{Introduction}

It is the goal of natural medicine researchers to trace active ingredients from natural products and then develop clinically effective drugs. The earliest drugs in human use have been obtained from natural products. From ancient times to the present, natural medicines have been developed and even now play an extremely important role in daily medication (1-3). It is reported that $25 \%$ of prescription drugs in the US contain active ingredients derived from plants. In 1973, 13.3\% and $2.7 \%$ were derived from microorganisms and animals, respectively. Half

Correspondence to: Professor Xiaoxin Zhu, Institute of Chinese Materia Medica, China Academy of Chinese Medical Sciences, No 16 Nan Xiao Jie, Dong Zhi Men Nei, Dong Cheng Qu, Beijing 100700, P.R. China

E-mail: zhuxx59@yahoo.com.cn

Key words: Stellera chamaejasme L., apoptosis, tumor, death receptor, natural product of the best-selling drugs in 1991 were from natural compounds or derivatives. To date, only $5-15 \%$ of the 250,000 types of higher plants have been screened (4). As such, natural medicine has great potential and much room for development.

Natural products have varied forms of biological activity. Anti-tumor activity is a very important research subject. Cancer treatment is a topical and complex area of modern study and chemotherapy remains a commonly used method for the treatment of cancer. More than $60 \%$ of cancer chemotherapeutic agents currently in use are natural products or derivatives (5) such as vincristine, paclitaxel and camptothecin. These anticancer drugs from natural products have been used clinically and the effects are quite significant (6).

Cell death by apoptosis eliminates excess, redundant or abnormal cells in animals and hence is crucial for animal development and tissue homeostasis. Disturbed regulation of this vital process represents a major causative factor in the pathogenesis of cancers (7). There are two apoptotic pathways: the death receptor pathway and the mitochondrial pathway. Death receptors are cell surface receptors that belong to the tumor necrosis factor (TNF) superfamily, which trigger apoptosis upon ligand binding. The best characterized death receptors are Fas (CD95/Apo1), TNF receptor 1 (p55), TRAMP (WSL-1/Apo3/DR3/LARD), TRAIL-R1 (DR4) and TRAIL-R2 (DR5/Apo2/KILLER). Death receptors contain an intracellular death domain (DD), which upon ligand binding (Fas ligand, TNF, TWEAK, TRAIL) associates with an adaptor protein called Fas-associated death domain (FADD) directly or indirectly via the TNFR-associated death domain (TRADD). FADD also interacts with pro-caspase- 8 to form the death inducing signaling complex (DISC) at the receptor. Once assembled, DISC induces the activation of caspase-8, which in turn precipitates the activation of downstream effector caspases (8-12). Therefore, promoting cell apoptosis via regulation of the TNF death receptor family proteins has been the main focus in the development of anti-cancer therapies.

Traditional Chinese medicine is an important part of the field of natural medicine and has a clear application in antitumor treatment. Stellera chamaejasme L. known as 'Rui Xiang Lang Du', a pungent Chinese herb, with the effects of detoxification, edema alleviation, elimination of slough and promotion of granulation, has long been used for the treatment of various 
tumors in the Chinese population. In a previously published study, we found that ethanol extract of Stellera chamaejasme L. (ESC) inhibited the growth of $\mathrm{H}_{22}$ and BEL-7402 tumor cells and induced apoptosis of BEL-7402 tumor cells in vitro and in vivo (13).

In this study, we obtained ESC-2 from ESC using a special isolation technique. In order to further trace and confirm the potential anti-cancer biological activity of Stellera chamaejasme L., we evaluated the inhibitory effect of ESC-2 on the growth of NCI-H157 human lung cancer cells and investigated the possible apoptotic molecular mechanisms mediating its biological effect in vitro.

\section{Materials and methods}

Materials and reagents. RPMI-1640 medium, fetal bovine serum (FBS), penicillin-streptomycin and Trypsin-EDTA were purchased from Gibco (Grand Island, NY, USA). Sulforhodamine B, propidium iodide (PI) and RNase were provided by Sigma Chemical Co. (St. Louis, MO, USA). A fluorescein isothiocyanate (FITC)-conjugated Annexin V apoptosis detection kit was provided by Becton-Dickinson (San Jose, CA, USA). Caspase- $3,-8$ colorimetric protease assay kits were purchased from Chemicon International, Inc. (Temecula, CA, USA). Fas, TRAIL-R1 ELISA kit were from R\&D Systems (Minneapolis, MN, USA). All the other chemicals used, unless otherwise stated, were obtained from Sigma Chemicals.

Preparation of the extract from Stellera chamaejasme L. Stellera chamaejasme L. herbal medicine was extracted three times with $100 \%$ ethanol and the resulting liquid (volatiled to ensure a non-alcohol status) was washed in a polyamide column with $60 \%$ ethanol, which were recycled decompressively and vacuum dried at room temperature. The compound finally obtained was ESC (13). ESC was mixed with reverse silica, filtered through a C18 column and eluted with $100 \%$ methanol; the final samples being ESC-2.

Cell culture. Human lung cancer NCI-H157 cells were obtained from the Cell Culture Center of the Chinese Academy of Medical Sciences. The cells were grown in RPMI-1640 medium containing 10\% (v/v) FBS and $100 \mathrm{U} / \mathrm{ml}$ penicillin and $100 \mu \mathrm{g} / \mathrm{ml}$ streptomycin in a $37^{\circ} \mathrm{C}$ humidified incubator with $5 \% \mathrm{CO}_{2}$. The cells were subcultured at $80-90 \%$ confluency. Cells used in this study were subjected to no more than 20 cell passages.

Evaluation of cell viability by the sulforhodamine $B$ assay. Cell viability was assessed by the sulforhodamine B (SRB) colorimetric assay. NCI-H157 cells were seeded into 96-well plates at a density of $0.5 \times 10^{4}$ cells $/$ well in $0.1 \mathrm{ml}$ medium. The cells were treated with various concentrations of ESC-2 for different time periods. Treatment with $0.2 \%$ DMSO was included as a vehicle control. Following addition of ESC-2, the plates were incubated for an additional $48 \mathrm{~h}$. The assay was terminated by the addition of cold trichloroacetic acid (TCA). Cells were fixed in situ by the addition of $50 \mu \mathrm{l}$ of cold $50 \%$ (w/v) TCA (final concentration, 10\%) and incubated for $1 \mathrm{~h}$ at $4^{\circ} \mathrm{C}$. Then $100 \mu \mathrm{l} \mathrm{SRB}$ solution at $0.4 \%(\mathrm{w} / \mathrm{v})$ in $1 \%$ acetic acid was added to each well, and the plates were incubated for $10 \mathrm{~min}$ at room temperature. Following staining, unbound dye was removed by washing five times with $1 \%$ acetic acid and the plates were air dried. Bound stain was subsequently solubilized with $10 \mathrm{mM}$ non-buffered tris-acetate (pH 10.5) and the absorbance was read on an automated plate reader (ELX800 type, Bio-Tex Instruments, Inc.) at a wavelength of $515 \mathrm{~nm}$. The inhibition rate (\%) was calculated as follows:

Inhibition rate $(\%)=1$ - mean absorbance of treatment group/mean absorbance of vehicle control group.

Observation of morphological changes. NCI-H157 cells were seeded into 96-well plates at a density of $0.5 \times 10^{5}$ cells/well in $0.1 \mathrm{ml}$ medium. The cells were treated with various concentrations of ESC-2 for $48 \mathrm{~h}$. Cell morphology was observed using an inverted microscope (Olympus, Japan). The images were captured at a magnification of $\times 200$.

Detection of apoptosis by flow cytometric analysis with PI staining. Following incubation with various concentrations of ESC- $2,1 \times 10^{5} / \mathrm{ml}$ cells were collected into a single-cell suspension. Pre-cooled $70 \%$ ethanol was added to fix cells at $4^{\circ} \mathrm{C}$ for $24 \mathrm{~h}$ or more. Cells were rinsed 2 times with $500 \mu \mathrm{l}$ PBS prior to being stained with a solution containing $50 \mu \mathrm{g} / \mathrm{ml}$ PI and $100 \mu \mathrm{g} / \mathrm{ml}$ RNase for $30 \mathrm{~min}$ in the dark, and subsequently apoptosis of the NCI-H157 cells was determined by flow cytometric analysis using a fluorescence-activated cell sorting (FACS) caliber (Becton-Dickinson, USA).

Observation of apoptosis by fluorescence microscopy with Annexin V/PI staining. Following incubation with various concentrations of ESC-2, apoptosis of NCI-H157 cells was observed by fluorescence microscopy and Annexin V-fluorescein isothiocyanate (FITC)/PI kit. Staining was performed according to the manufacturer's instructions. The early apoptotic cells were labeled by green fluorescence (FITC-labeled), while the late apoptotic cells were labeled by both green and red fluorescence (the latter PI-labeled).

Analysis of caspase activation. The activities of caspase- 3 and -8 were determined by a colorimetric assay using the caspase- 3 and -8 activation kits, following the manufacturer's instructions. Briefly, following treatment with various concentrations of ESC-2 for $24 \mathrm{~h}, \mathrm{NCI}-\mathrm{H} 157$ cells were lysed with provided lysate buffer for $30 \mathrm{~min}$ on ice. The lysed cells were centrifuged at $16,000 \mathrm{xg}$ for $10 \mathrm{~min}$, and $100 \mu \mathrm{g}$ of the protein was incubated with $50 \mu \mathrm{l}$ of the colorimetric tetrapeptides, Asp-Glu-Val-Asp (DEAD)-p-nitroaniline (pNA) (specific substrate of caspase-3) or Ile-Glu-Thr-Asp (IETD)-pNA (specific substrate of caspase-8) at $37^{\circ} \mathrm{C}$ in the dark for $2 \mathrm{~h}$. Samples were read at $405 \mathrm{~nm}$ in an ELISA reader (BioTek, Model EXL800, USA). The data were normalized to the activity of the caspases in the control cells (treated with $0.5 \%$ DMSO vehicle) and presented as the fold of the control.

ELISA analysis. The level of Fas and TRAIL-R1 in the cells was determined using an enzyme-linked immunosorbent assay (ELISA) kit according to the manufacturer's protocol. Briefly, the cell supernatant together with 9-times sample buffer $(100 \mu \mathrm{l})$ were added to the corresponding sample well of the microtiter plate. Plates were incubated at $37^{\circ} \mathrm{C}$ 

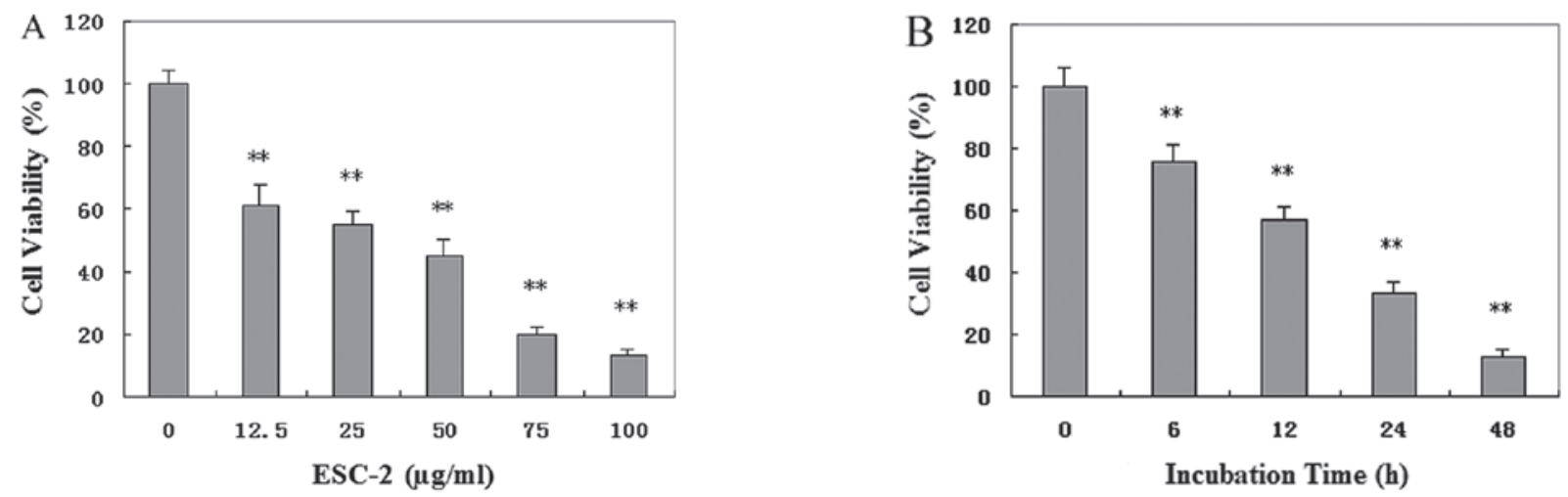

Figure 1. Effect of ESC-2 on the viability of NCI-H157 cells. (A) NCI-H157 cells were treated with the indicated concentrations of ESC-2 for 48 h. (B) Cells were treated with $50 \mu \mathrm{g} / \mathrm{ml}$ of ESC-2 for the indicated time periods. Cell viability was determined by the SRB assay. The data were normalized to the viability of control cells (100\%, treated with $0.2 \%$ DMSO vehicle). Data are averages with SD (error bars) from at least three independent experiments. ${ }^{*} \mathrm{P}<0.05$, ${ }^{* * *} \mathrm{P}<0.01$, significant versus control cells.
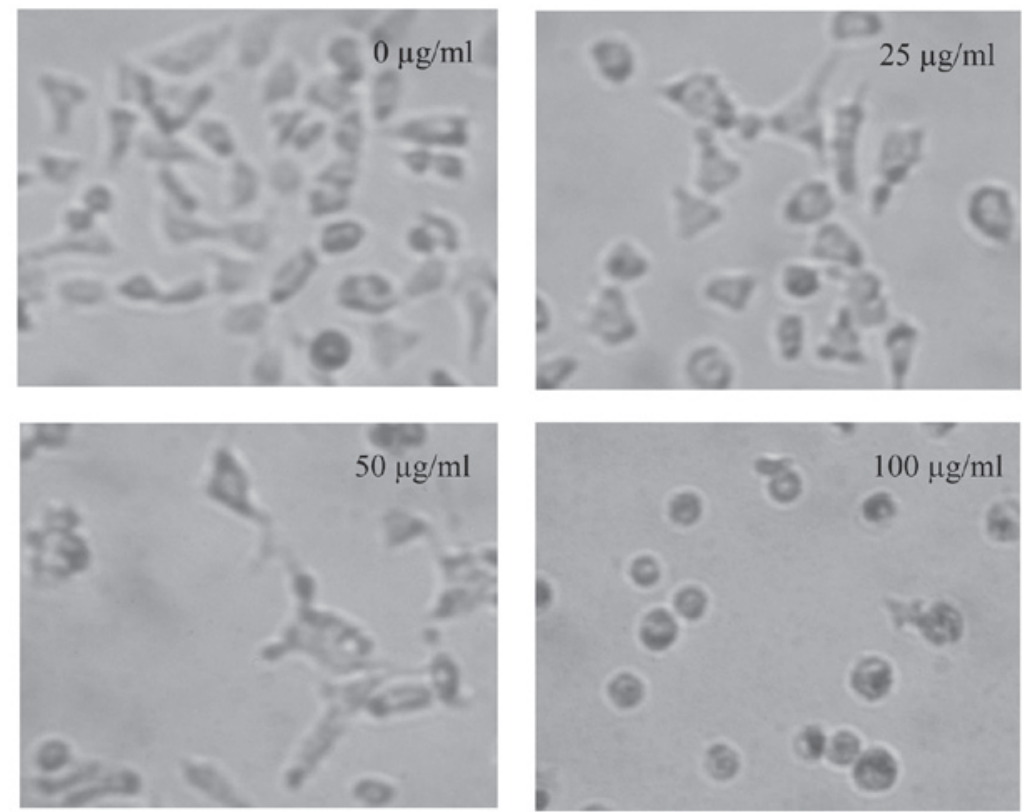

Figure 2. Effect of ESC-2 on the morphological changes of NCI-H157 cells. NCI-H157 cells were treated with the indicated concentrations of ESC-2 for $24 \mathrm{~h}$ and morphological changes were observed using inverted microscopy. The images were captured at a magnification of x 200 . Images are representative of three independent experiments.

for $2 \mathrm{~h}$. When the antigens present in the sample had bound to the coating antibodies adsorbed in the microwells, the plates were washed with $100 \mu \mathrm{l}$ of wash buffer five times. Microtiter plates to which were added $100 \mu$ l biotinylated antibody were incubated at $37^{\circ} \mathrm{C}$ for $1 \mathrm{~h}$. Plates were washed again. Conjugated enzymes $(100 \mu \mathrm{l})$ were added to bind to antigens captured by the biotinylated antibody. Following the removal of unbound conjugated enzyme antibody by the same washing steps, $100 \mu \mathrm{l}$ TMB solution was added. Following incubation at room temperature in the dark for $15 \mathrm{~min}$, the reaction was stopped by adding $100 \mu 1$ stop solution, and the absorbance was measured at $450 \mathrm{~nm}$ with a microplate reader. The concentrations of Fas and TRAIL-R1 in the samples were determined on the base of a standard curve prepared from seven standard dilutions. All samples were analyzed in duplicate, and the limit of detection was determined to be $15 \mathrm{pg} / \mathrm{ml}$.
Statistical analysis. All data are the means of three determinations and data were analyzed using the SPSS Package for Windows (Version 12). Statistical analysis of the data was performed with ANOVA. Differences with $\mathrm{P}<0.05$ were considered statistically significant.

\section{Results}

ESC-2 inhibits the growth of NCI-H157 cells. The effect of ESC-2 on the viability of NCI-H157 cells was determined by SRB assay. As shown in Fig. 1A, treatment with 12.5-100 $\mu \mathrm{g} / \mathrm{ml}$ of ESC-2 for $48 \mathrm{~h}$ dose-dependently reduced cell viability by 13.26-61.49\% compared to the untreated control cells $(\mathrm{P}<0.01)$, with an estimated half-maximal inhibitory concentration $\left(\mathrm{IC}_{50}\right)$ value of $50 \mu \mathrm{g} / \mathrm{ml}$. The cell viability was decreased to $61.49 \%$ at the highest concentration of ESC-2 $(100 \mu \mathrm{g} / \mathrm{ml})$ in this study. We also evaluated the effect of $50 \mu \mathrm{g} / \mathrm{ml}$ of ESC-2 ( $\mathrm{IC}_{50}$ value) on 

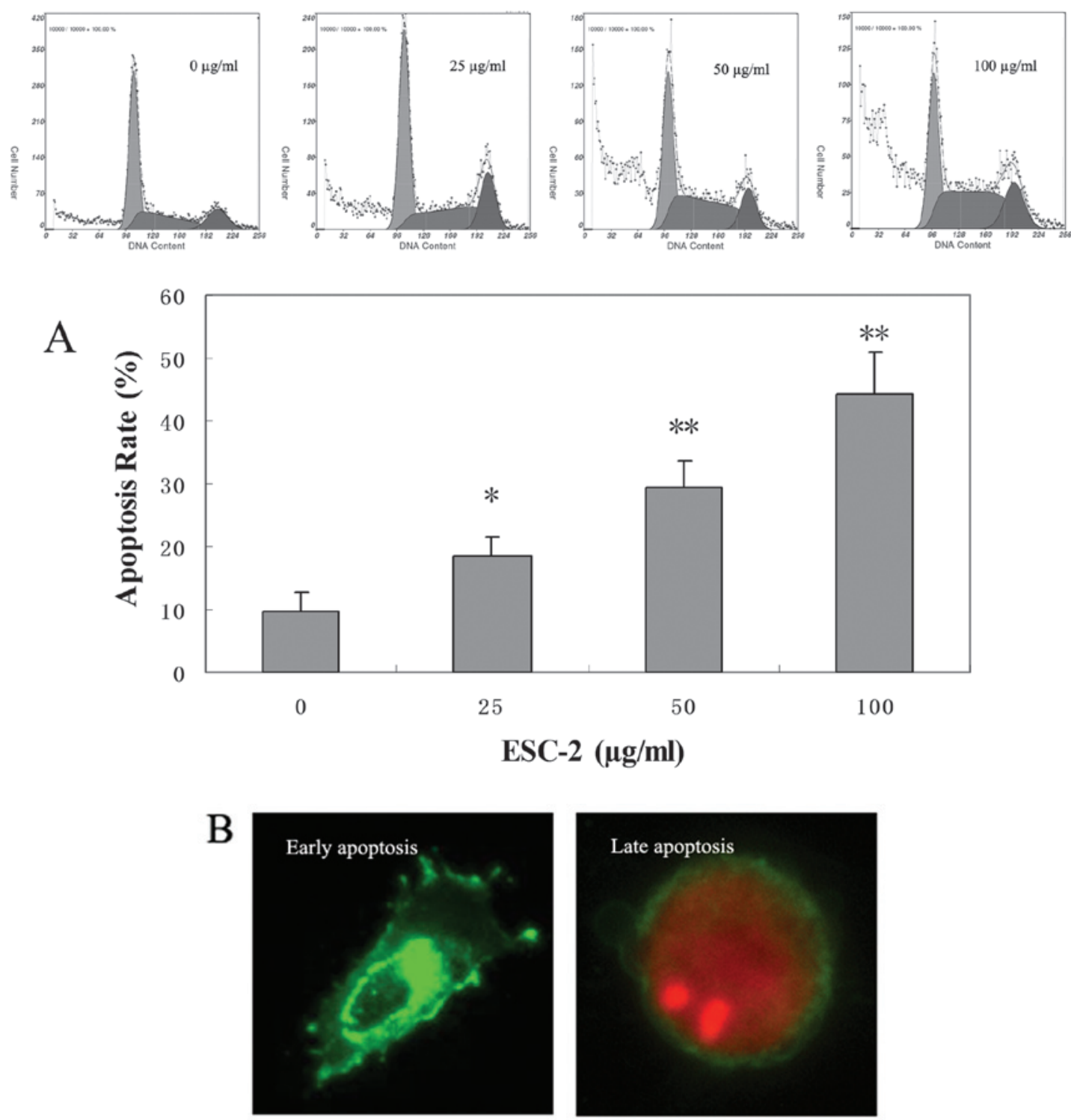

Figure 3. Apoptosis induced by ESC-2 in NCI-H157 cells. (A) NCI-H157 cells were treated with the indicated concentrations of ESC-2 for $24 \mathrm{~h}$ and apoptosis rates were observed using flow cytometry. Data are averages with $\mathrm{SD}$ (error bars) from at least three independent experiments. " $\mathrm{P}<0.05$, ${ }^{* *} \mathrm{P}<0.01$, significant versus control cells. (B) Cells were treated with $50 \mu \mathrm{g} / \mathrm{ml}$ of ESC-2 for $24 \mathrm{~h}$ and apoptotic phenomena were observed with fluorescence microscope. Early apoptotic cells were labeled by green fluorescence (FITC-labeled), while the late apoptotic cells were labeled by both green and red fluorescence (the latter PI-labeled). The images were captured at a magnification of x200.

cell viability with incubation for different periods of time. As shown in Fig. 1B, treatment with $100 \mu \mathrm{g} / \mathrm{ml}$ of ESC-2 led to a gradual decrease in cell viability with the increase of exposure time. These results suggest that ESC-2 inhibits NCI-H157 cell growth or viability in a dose-and time-dependent manner. To further verify these results, we evaluated the effect of ESC-2 on NCI-H157 cell morphology via inverted microscopy, since cell morphology in culture is indicative of the healthy status of the cells. As shown in Fig. 2, untreated NCI-H157 cells appeared as densely packed and disorganized multilayers, whereas following incubation with various concentrations of ESC-2 for $24 \mathrm{~h}$ a number of the cells became rounded and shrunken, and detached from each other or floated in the medium. In addition, after a $24 \mathrm{~h}$ exposure to ESC-2, the cells became less confluent. Taken together, these data demonstrate that ESC-2 inhibits the growth of NCI-H157 cells.
ESC-2 induces apoptosis of NCI-H157 cells. To determine whether the cell-growth suppressive effect of ESC-2 is due to apoptosis, we examined the pro-apoptotic activity of ESC-2 in NCI-H157 cells via PI staining followed by FACS analysis. As shown in Fig. 3A, the percent of cells undergoing apoptosis following treatment with $0,25,50$ and $100 \mu \mathrm{g} / \mathrm{ml}$ of ESC-2 for $24 \mathrm{~h}$ was 5.68, 18.57, 29.54 and $44.13 \%$, respectively ( $\mathrm{P}<0.05$, versus untreated control cells). This indicates that ESC-2 treatment induces NCI-H157 cell apoptosis in a dose-dependent manner. To confirm the pro-apoptotic function of ESC-2, we further investigated the pro-apoptotic effect of ESC-2 with Annexin/PI double staining. As shown in Fig. 3B, NCI-H157 cells treated with $50 \mu \mathrm{g} / \mathrm{ml}$ of ESC-2 ( $\mathrm{IC}_{50}$ value) for $24 \mathrm{~h}$ displayed the characteristic green and red fluorescent staining of early and late apoptosis. 

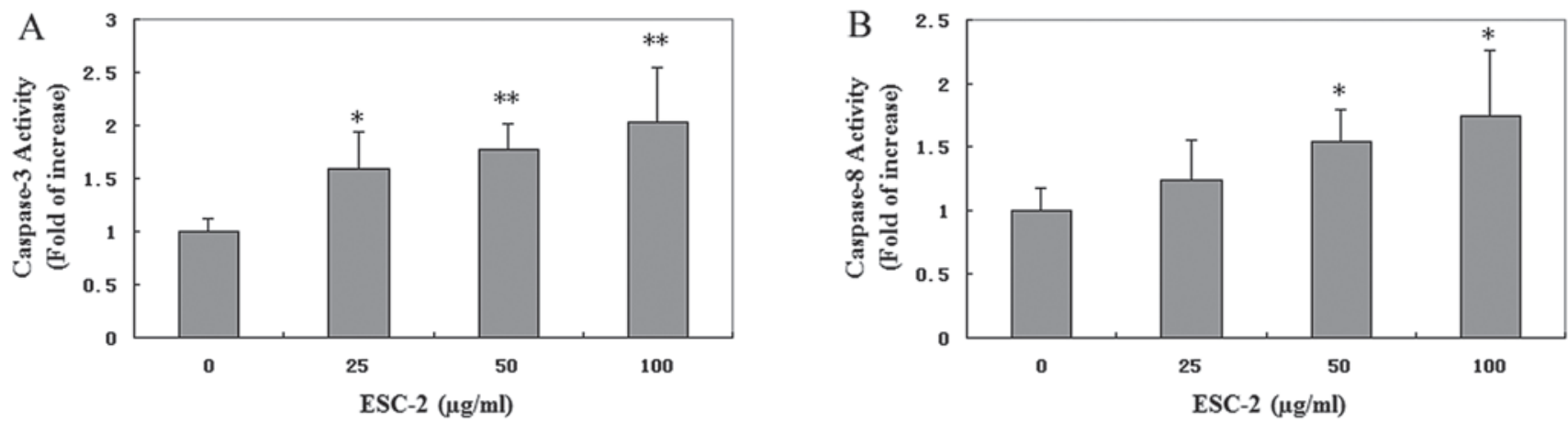

Figure 4. Effect of ESC-2 on the activity of caspases in NCI-H157 cells. The cells were treated with the indicated concentrations of ESC-2 for 24 h. Caspase-3 and -8 activities were determined by a colorimetric assay. The data were normalized to the caspase activities within control cells (treated with $0.2 \%$ DMSO vehicle) and represented as fold of control. Data are averages with SD (error bars) from at least three independent experiments. ${ }^{*} \mathrm{P}<0.05$, ${ }^{* *} \mathrm{P}<0.01$, significant versus control cells.
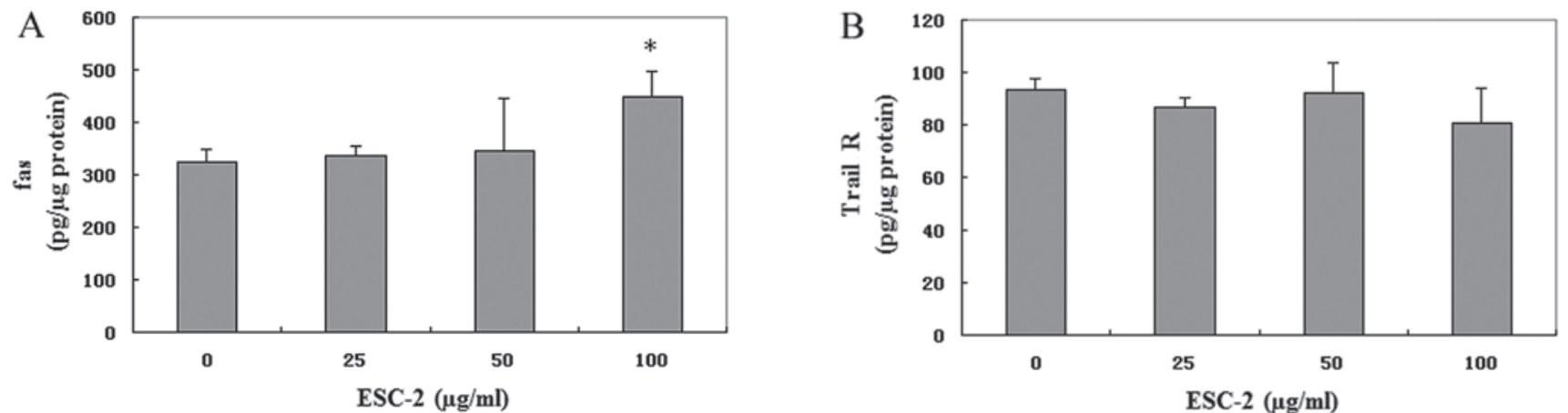

Figure 5. Effect of ESC-2 on the death receptor protein expression in NCI-H157 cells. The cells were treated with the indicated concentrations of ESC-2 for $24 \mathrm{~h}$. Fas and Trail-R expression was determined by ELISA assay. Data are averages with SD (error bars) from at least three independent experiments. ${ }^{*} \mathrm{P}<0.05$, ${ }^{* *} \mathrm{P}<0.01$, significant versus control cells.

ESC-2 induces activation of caspase- 8 and -3 . To identify the downstream effectors in the apoptotic signaling pathway, the activation of caspase- 8 and -3 was examined by a colorimetric assay using specific chromophores, DEVD-pNA (specific substrate of caspase-3) and IETD-pNA (specific substrate of caspase-8). As shown in Fig. 4A and B, ESC-2 treatment significantly and dose-dependently induced activation of both caspase- 8 and -3 in the NCI-H157 cells $(\mathrm{P}<0.01$ or 0.05 , versus untreated control cells). These data suggest that ESC-2 promotes NCI-H157 cell apoptosis via the death receptor-dependent pathway.

ESC-2 regulates the expression of Fas and TRAIL-R. To further study the mechanism of the anti-cancer activity of ESC-2, we examined the protein expression level of death receptor of Fas and TRAIL-R1 in ESC-treated NCI-H157 cells using the ELISA assay. The results showed that ESC-2 treatment profoundly increased Fas expression (Fig. 5A), while it did not obviously influence TRAIL-R1 expression in NCI-H157 cells (Fig. 5B).

\section{Discussion}

In recent years, traditional Chinese herbal remedies have gradually gained considerable attention as a new source of anti-cancer drugs. Although their healing mechanisms are still largely unknown, some of the drugs have been used advantageously to help cancer patients fight their disease when compared to other treatments (14). Stellera chamaejasme L. is one of these herbs, widely used in the Chinese population to treat various types of cancer and other diseases. Our previously published study confirmed that extracts of Stellera chamaejasme L. (ESCs) have significant anti-tumor effects in vitro and in vivo $(13,15)$. Here, we reported that ESC-2 (extracted from ESC) reduces the viability and inhibits growth of NCI-H157 cells in a dose-and time-dependent fashion and may be a potential anti-tumor drug candidate. Therefore, since ESC-2 is able to be further developed as an anti-cancer agent, its underlying molecular mechanism should be elucidated. Cytotoxic drugs often used in chemotherapy of tumors cause apoptosis in target cells. In this study, we demonstrated that these anti-cancer effects on NCI-H157 cells resulted from the induction of apoptosis by ESC-2.

We used Annexin V/PI double staining to observe the apoptotic phenomena and PI single staining to assess the apoptosis rate in NCI-H157 cells. Our data clearly showed that treatment with ESC-2 leads to apoptosis in a dose-dependent manner.

Caspases, represented by a family of cysteine proteases, are the key proteins that modulate the apoptotic response. Caspase-3 is a key executioner of apoptosis, which is activated by an initiator caspase such as caspase- 8 during death receptormediated apoptosis (16). In the present study, we found that 
ESC-2 induces the activation of both caspase- 8 and -3 in NCI-H157 cells in a dose-dependent manner. Thus, ESC-2induced NCI-H157 cell death is accompanied by an increase in the activities of caspase- 8 and -3 , which then stimulates the molecular cascade for apoptosis.

Death receptor-dependent apoptosis is mainly regulated by tumor necrosis factor superfamily proteins. In this study, we detected the two classical death receptor, Fas and TRAIL-R1, in NCI-H157 cells.

The Fas (APO-1/CD95)/Fas ligand (CD95-L) system is a key regulator of apoptosis (17). Fas is also known as CD95, Apo-1, and tumor necrosis factor receptor superfamily, member 6 (TNFRSf6). Fas is located on chromosome 10 in humans and 19 in mice. Similar sequences related by evolution (orthologs) are found in most mammals (18). Studies have shown that increased expression of fas protein on the tumor cell surface can promote apoptosis of tumor cells (19). Here we describe that ESC-2 induces apoptosis via upregulation of Fas expression in the human NCI-H157 cell line. The finding that apoptosis caused by ESC-2 may be mediated via the Fas system provides a molecular insight into the research of the mechanisms of ESC-2 in tumor treatment. TRAIL-R is another death receptor recently identified that also belongs to the tumor necrosis factor receptor superfamily. It activates caspase- 8 to induce apoptosis by binding its ligand TRAIL (20). To date, five types of TRAIL receptors have been identified: TRAILR1, TRAIL-R2, TRAIL-R3, TRAIL-R4 and OPG. TRAIL-R1 and TRAIL-R2 have a death domain and are able to transfer apoptotic signals and subsequently induce apoptosis $(21,22)$. In the present study, we evaluated TRAIL-R1 expression. The results showed that ESC-2 did not obviously influence TRAIL-R1 expression. We suggest that the regulating mechanism of ESC-2 in apoptosis is complex, and the pro-apoptotic effect of ESC-2 may be the result of the integrated regulation of the tumor apoptosis pathway protein expression.

\section{Acknowledgements}

This work was supported by the China Postdoctoral Foundation (No. 20090450550); Optional Research Project sponsored by China Academy of Chinese Medical Science (No. Z02065); Sino-French Cooperation Project of State Administration of Traditional Chinese Medicine.

\section{References}

1. Holt GA and Chandra A: Herbs in the modern healthcare environment - an overview of uses, legalities, and the role of the healthcare professional. Clin Res Regul Aff 19: 83-107, 2002.

2. Cragg GM and Newman DJ: Natural product drug discovery in the next millennium. Pharmaceut Biol 39: 8-17, 2001.

3. Newman DJ, Cragg GM and Snader KM: The influence of natural products upon drug discovery. Nat Prod Rept 17: 215-234, 2000.

4. Cragg GM, Newman DJ and Snader KM. Natural products in drug discovery and development. J Nat Prod 60: 52-60, 1997.
5. Nagle DG, Zhou YD, Mora FD, Mohammed KA and Kim YP: Mechanism targeted discovery of antitumor marine natural products. Curr Med Chem 11: 1725-1756, 2004.

6. Srivastava V, Negi AS, Kumar JK, Gupta MM and Khanuja SP: Plant-based anticancer molecules: a chemical and biological profile of some important leads. Bioorg Med Chem 13: 5892-5908, 2005.

7. Reed JC: Mechanisms of apoptosis. Am J Pathol 157: 1415-1430, 2000.

8. Thompson CB: Apoptosis in the pathogenesis and treatment of disease. Science 267: 1456-1462, 1995.

9. Dhein J, Walczak H, Bäumler C, Debatin KM and Krammer PH:Autocine T-cell suicide mediated by APO-1/(Fas/ CD95). Nature 373: 438-441, 1995.

10. Kitson J, Raven T, Jiang YP, Goeddel DV, Giles KM, Pun KT, Grinham CJ, Brown R and Farrow SN: A death-domaincontaining receptor that mediates apoptosis. Nature 384: 372-375, 1996

11. Pan G, O'Rourke K, Chinnaiyan AM, Gentz R, Ebner R, Ni J and Dixit VM. The receptor for the cytotoxic ligand TRAIL. Science 276: 111-113, 1997.

12. Thorburn A: Death receptor-induced cell killing. Cell Signal 16: 139-144, 2004

13. Liu X, Li Y, Yang Q, Liu A and Zhu X: Anti-tumor effect of alcohol extract of Stellera chamaejasme $\mathrm{L}$ in vitro. Zhongguo Zhong Yao Za Zhi 35: 3048-3051, 2010 (In Chinese).

14. Zhu JY, Lavrik IN, Mahlknecht U, Giaisi M, Proksch P, Krammer PH and Li-Weber M: The traditional Chinese herbal compound rocaglamide preferentiallyinduces apoptosis in leukemia cells by modulation of mitogen-activated protein kinase activities. Int J Cancer 121: 1839-1846, 2007.

15. Pan GF, Yang Q, Liu A and Zhu XX: Antitumor activities of active components alignments isolated from Stellera Chamaejasme L in H22-bearing mice. China J Trad Chin Med Pharma 4: 438-442, 2009.

16. Fan TJ, Han LH, Cong RS and Liang J: Caspase family proteases and apoptosis. Acta Biochim Biophys Sin 37: 719-727, 2005.

17. Kawasaki M, Kuwano K, Nakanishi Y, Hagimoto N, Takayama K, Pei XH, Maeyama T, Yoshimi M and Hara N: Analysis of Fas and Fas ligand expression and function in lung cancer cell lines. Eur J Cancer 36: 656-663, 2000.

18. Wajant H: The Fas signaling pathway: more than a paradigm. Science 296: 1635-1636, 2002.

19. Nadal C, Maurel J, Gallego R, Castells A, Longarón R, Marmol M, Sanz S, Molina R, Martin-Richard M and Gascón P: FAS/FASL ligand ratio: a marker of oxaliplatin-based intrinsic and acquired resistance in advanced colorectal cancer. Clin Cancer Res 11: 4770-4774, 2005.

20. LeBlanc HN and Ashkenazi A: Apo2L/TRAIL and its death and decoy receptors. Cell Death Differ 10: 66-75, 2003.

21. Kimberley FC and Screaton GR: Following a TRAIL: update on a ligand and its five receptors. Cell Res 14: 359-372, 2004.

22. Spierings DC, de Vries EG and Vellenga E: Tissue distribution of the death ligand TRAIL and its receptors. J Histochem Cytochem 52: 821-831, 2004. 